\title{
Formation and Its Mechanism of High-speed Micro-grooving on Metal Surface by Angled CW Laser Irradiation
}

\author{
Nozomi Taura ${ }^{1}$, Akiya Mitsunobu $^{2}$, Tatsuhiko Sakai ${ }^{3}$, Yasuhiro Okamoto*1, and Akira Okada ${ }^{1}$ \\ ${ }^{1}$ Graduate School of Natural Science and Technology, Okayama University, Japan \\ ${ }^{2}$ Faculty of Engineering, Okayama University, Japan \\ ${ }^{3}$ NIPPON STEEL CORPORATION, Japan \\ *Yasuhiro.Okamoto@okayama-u.ac.jp
}

\begin{abstract}
In general, pulsed lasers with high peak power have been used for the micro-groove formation. However, the processing speed is limited by the pulse repetition rate. On the other hand, CW laser can be expected to perform the high-speed processing by continuous energy input. The mechanism of micro-groove formation by CW laser was investigated by high-speed observation and the thermal fluid analysis. In the perpendicular irradiation of CW laser, the molten metal flows symmetrically around the keyhole to the backward direction, and micro-grooves remain at both edges of molten region. In contrast, in the angled irradiation, the molten metal at the reflection-side scatters as spatters. The remained molten metal flows from the reflection-side to the incident-side through the bottom of keyhole, since the recoil pressure is generated from the reflection-side to the incident-side. In addition, high-speed scanning contributes to keeping the sufficient time and force to move the molten metal in the backward direction. Then, the micro-groove remains at the reflection-side, while the upheaval is formed at the incident-side by gathering the molten metal from the reflection-side and the front of keyhole. Asymmetrical behavior of molten metal flow in angled irradiation of CW laser can create micro-groove in the reflection-side.
\end{abstract}

DOI: $10.2961 / \mathrm{jlmn} .2021 .02 .2006$

Keywords: CW laser, micro-groove, high-speed scanning, thermal fluid analysis, high-speed observation

\section{Introduction}

Laser scribing has been applied to the improvement of surface functions and the cleavage process with sufficient large depth of groove [1-3]. Compared with mechanical machining process, laser scribing is widely used in practical applications, because its machinability is independent of material's hardness. In addition, the processing load can be minimized owing to a non-contact process.

In general, laser scribing has been performed by using a pulsed oscillation because of its high peak-power, which can remove parts of materials by the evaporation to create the micro-groove easily [4-7]. Appropriate assist gas flow can improve the scribing performance [8], but its processing speed is limited by the pulse repetition rate. On the other hand, high-speed processing is expected by using CW oscillation, which can output laser energy continuously, although its power is lower than that of pulsed oscillation. When high-speed scanning of a relatively low-averagepower CW laser is carried out by the perpendicular irradiation to the specimen surface, undercuts are generated at both edges of molten bead and remained as shallow micro-grooves [9]. On the other hand, when the CW laser beam is inclined, asymmetrical processing phenomena result in a formation of asymmetrical undercuts. The comparatively deeper undercut remains as a micro-groove on the surface of material [10,11]. In addition, it is reported that the micro-grooving by using $\mathrm{CW}$ laser generates the upheaval of molten metal at the incidentside of laser beam. When the specimen is used as a joining component, the upheaval and micro-groove can be used to improve the bonding strength owing to their anchoring effects [12]. It had been reported that the relationship between the bonding strength and surface structures was experimentally and theoretically investigated in the pulsed laser processing [13, 14]. However, the micro-groove shape by low-average-power CW laser is different from that obtained by the pulsed laser, and the detailed formation mechanism of the micro-groove had not been clarified yet. One of micro-grooving applications is the improvement of joining characteristics between metal and plastics, which is widely used in the aerospace and automobile industry. If high-speed micro-grooving on the surface of metal could be performed by low-average-power CW laser, this process would open new applications of various materials and products.

Therefore, in this study, the formation mechanism of micro-groove by the angled irradiation of CW laser was experimentally and numerically investigated to improve the controllability of micro-groove shape on the surface of metal. In order to discuss the phenomena of microgrooving formation on the surface of metal, two approaches were considered. One is the thermal fluid analysis, which can represent the flow of molten metal as a liquid with a free interface by considering the fluid rate in each cell. The other is the high-speed observation around the laser irradiation area. The formation mechanism of the micro-groove was clarified by comparing and discussing these results. 


\section{Analytical and experimental procedures}

\subsection{Analytical procedures}

In order to quantitatively understand the phenomena of micro-grooving, the thermal fluid analysis was conducted by a general computational fluid dynamics software "FLOW-3D Ver. 11.2, Flow Science Japan”. The temperature filed is calculated with considering the thermophysical properties of the material, and the associated flow of the molten material was also discussed by using VOF (Volume-of-Fluid) method and FAVOR (Fractional AreaVolume Obstacle Representation) method, which can deal with the free surface flow $[15,16]$.

In this analysis, the material is treated as a fluid. It should be noted that solid phase material cannot move below the solidus temperature, and liquid phase material behaves as the fluid above the melting temperature. To represent the flow of a fluid material with a free interface over time, the fluid volume per unit volume is calculated by equation (1).

$$
\begin{aligned}
\frac{\partial F}{\partial t}+\frac{1}{V_{\mathrm{F}}}\left\{\frac{\partial}{\partial x}\left(F A_{\mathrm{x}} u\right)+\frac{\partial}{\partial y}\left(F A_{\mathrm{y}} v\right)+\frac{\partial}{\partial z}\left(F A_{\mathrm{z}} w\right)\right\} \\
=F D I F+F S O R
\end{aligned}
$$

$$
\begin{array}{ll}
(x, y, z) & : \text { Coordinate directions } \\
(u, v, w) & : \text { Velocity components } \\
t & : \text { Time } \\
F & : \text { Fluid ratio to cell aperture volume } \\
V_{\mathrm{F}} & : \text { Volume aperture ratio } \\
A_{\mathrm{O}} & : \text { Cell aperture area } \\
F S O R & : \text { Fluid upwelling and suction term } \\
F D I F & : \text { Diffusion term in fluid rate } F
\end{array}
$$

Volume aperture ratio $V_{\mathrm{F}}$ and cell aperture area $A_{0}$ are shown in the Fig. 1. $A_{0}$ indicates the area ratio of material section to a side surface of one cell, and this area ratio is considered for all sides with the interface between liquid material and air in $x, y$, and z-directions, which are $A_{x}, A_{y}$, and $A_{\mathrm{z}}$, respectively. $V_{\mathrm{F}}$ is the volume ratio of material in one cell, and the volume aperture ratio $V_{\mathrm{F}}$ is expressed by equation (2).

$$
V_{\mathrm{F}}=V_{\mathrm{o}} / V_{\mathrm{C}}
$$

$V_{\mathrm{o}}$ and $V_{\mathrm{c}}$ are cell aperture volume and cell volume, and cell aperture volume $V_{\mathrm{o}}$ is the volume of the cell that fluid exists.

Figure 2 shows the thermal fluid analytical model, and the incident angle of laser beam $\theta_{\mathrm{i}}$ was set to 0 degree and 60 degrees. Hereafter, the area of $+x$ coordinate is expressed as an incident-side, while the opposite area of $-x$ coordinate is defined as a reflection-side. In this study, mild steel of SS400 in JIS specification was used as a specimen. Chemical compositions of SS400 are shown in Table 1. The size of SS400 area in the analytical model was set to be large enough to represent the micro-grooving area obtained from the experiment of laser irradiation. An air layer was assumed above the SS400 solid phase, and an atmospheric pressure boundary was applied to the specimen surface. At the other boundaries, the thermal insulation boundaries were applied to prevent the heat and fluid transfer outside the boundaries. The edge length of cube cell was set to $2 \mu \mathrm{m}$ in this model. The scan of laser beam was started at $150 \mu \mathrm{m}$ right from the left edge of analytical model.

Table 2 shows the analytical conditions of laser irradiation, and Table 3 lists thermophysical properties of SS400 in thermal fluid analysis. The incidence angle of laser beam in the plane perpendicular to the scanning axis was defined as $\theta_{\mathrm{i}}=0^{\circ}$, when the laser beam was irradiated vertically on the specimen surface. The laser beam used in this analysis was a continuous wave of Gaussian mode, and the spot diameter was $18 \mu \mathrm{m}$, which was obtained at the specimen surface by using a focusing lens of $100 \mathrm{~mm}$ focal length. The laser beam was scanned in $+y$ direction at an output power of $200 \mathrm{~W}$ and a high scanning speed of 2.0 $\mathrm{m} / \mathrm{s}$. These irradiation conditions in the thermal fluid analysis were equivalent to the experimental one as described later. In Table 3, density, specific heat, and thermal conductivity were values at room temperature, and viscosity and surface tension were represented at the melting point. Thermal fluid analysis dealt with the temperature dependent characteristics of density, specific heat, and thermal conductivity from room temperature to the boiling point. The viscosity and surface tension were treated from the melting point to the boiling point in this analysis $[17,18]$.

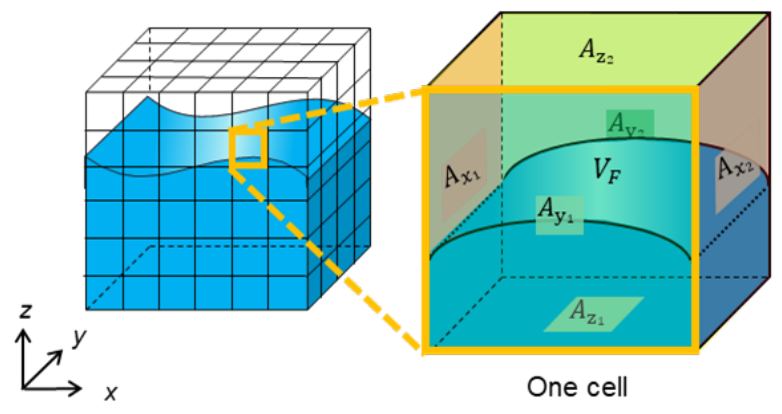

Fig. 1 Volume aperture ratio $V_{\mathrm{F}}$ and cell aperture area $A_{\mathrm{o}}$.

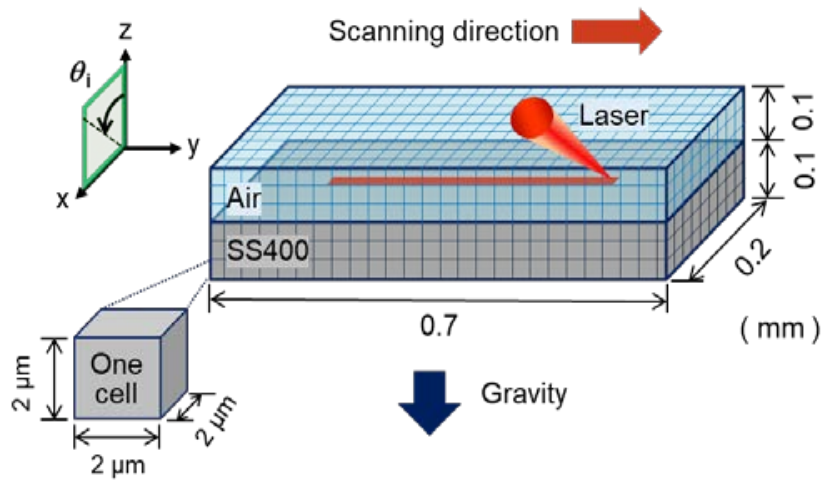

Fig. 2 Thermal fluid analytical model in laser irradiation to SS400.

Table 1 Chemical compositions of SS400 (wt. \%)

\begin{tabular}{cccccc}
\hline $\mathrm{C}$ & $\mathrm{Si}$ & $\mathrm{Mn}$ & $\mathrm{P}$ & $\mathrm{S}$ & $\mathrm{Fe}$ \\
\hline- & - & - & $<0.05 \%$ & $<0.05 \%$ & Bal. \\
\hline
\end{tabular}


Table 2 Analytical conditions of laser irradiation to SS400

\begin{tabular}{cc}
\hline Laser power $(\mathrm{W})$ & 200 \\
Laser emission type & $\mathrm{CW}$ \\
Beam diameter $(\mathrm{mm})$ & $\Phi 7$ \\
Spot diameter $(\mu \mathrm{m})$ & $\Phi 18$ \\
Laser intensity distribution & Gaussian \\
Focal length $(\mathrm{mm})$ & 100 \\
Scanning speed $(\mathrm{m} / \mathrm{s})$ & 2.0 \\
Irradiation time $(\mathrm{ms})$ & 200 \\
Specimen & $\mathrm{SS} 400$ \\
Cell size $(\mu \mathrm{m})$ & 2.0 \\
Incident angle $\theta_{\mathrm{i}}\left(^{\circ}\right)$ & 0,60 \\
\hline
\end{tabular}

Table 3 Thermophysical properties of SS400

\begin{tabular}{cc}
\hline Density $\left(\mathrm{kg} / \mathrm{m}^{3}\right)$ & $7.86 \times 10^{3}$ \\
Specific heat $(\mathrm{kJ} /(\mathrm{kg} \cdot \mathrm{K}))$ & 0.486 \\
Thermal conductivity $(\mathrm{W} /(\mathrm{m} \cdot \mathrm{K}))$ & 51.9 \\
Viscosity $(\mathrm{mPa} \cdot \mathrm{s})$ & 6.0 \\
Surface tension $\left(\mathrm{g} / \mathrm{s}^{2}\right)$ & 1872 \\
Melting point $(\mathrm{K})$ & 1811 \\
Boiling point $(\mathrm{K})$ & 3143 \\
Absorption rate $(\%)$ & 35 \\
\hline
\end{tabular}

\subsection{Experimental procedures}

The laser irradiation area to form micro-groove was observed by using a high-speed video camera (KEYENCE, High-speed microscope, VW-9000). Figure 3 schematically shows the setup of high-speed observation. In Fig. 3 (a), high-speed camera was set from the direction of scanning axis, in order to discuss the scattering behavior of spatter on the plane perpendicular to scanning axis. In Fig. 3 (b), high-speed camera was set almost directly above the scanning axis, in order to observe the molten metal flow around the keyhole. LED illumination of $850 \mathrm{~nm}$ wavelength was used, and a bandpass filter with a center wavelength of $880 \mathrm{~nm}$ and a protective glass were placed in the front of high-speed camera lens. The laser oscillator used in the experiment was a single-mode $\mathrm{Yb}$ fiber laser of $1085 \mathrm{~nm}$ wavelength. Irradiation experiments were conducted under the same conditions as the thermal fluid analysis. The micro-groove formation phenomena of microgroove were experimentally investigated by observing molten metal behavior in the green dotted line areas of Figs. 3 (a) and (b). In the experiments, at least 10 experiments are conducted under the same conditions, and the average results are recorded as the results of experiments.

\section{Results and discussion}

3.1 Comparisons of molten metal behavior in thermal fluid analysis results by perpendicular and angled irradiations

Molten metal behavior is discussed by considering the thermal fluid analysis results in this section. Figure 4 shows $3 \mathrm{D}$ view of molten metal behavior by perpendicular irradiation of $\theta_{\mathrm{i}}=0^{\circ}$. Figure 5 is the calculation result by the angled irradiation of $\theta_{\mathrm{i}}=60^{\circ}$. The positions of laser beams are schematically represented in both figures. The contour means liquid fraction rate, in which blue color shows solid phase, and red one represents liquid phase. In the case of perpendicular irradiation, the symmetrical flow of molten metal to the scanning axis can be observed in the rear of irradiation area. On the other hand, in the case of angled irradiation, the spatters are scattered in the reflection- side, and the molten metal flow is asymmetric in the rear of irradiation area. The angled irradiation generates unique molten metal flow.

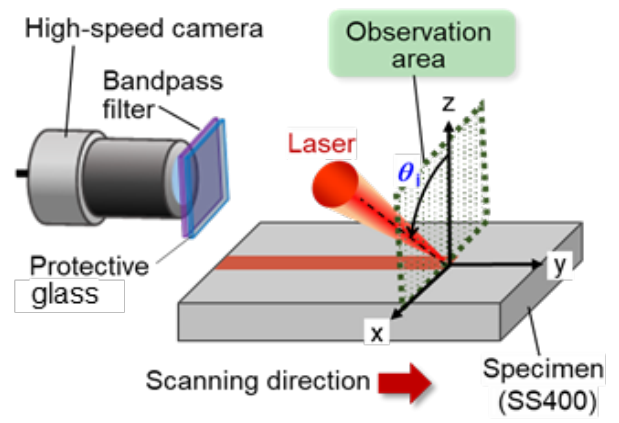

(a) Observation setup of irradiation area from side

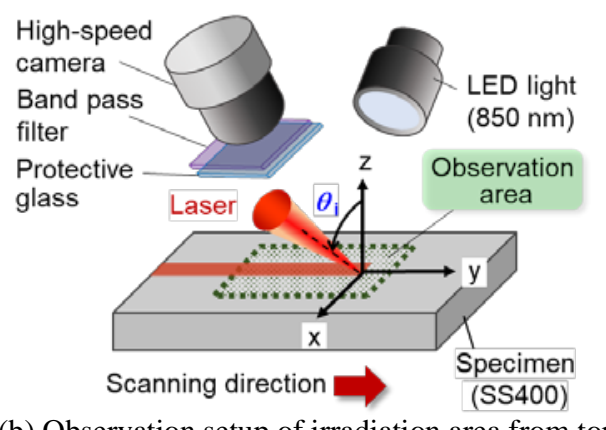

(b) Observation setup of irradiation area from top

Fig. 3 Experimental setups of laser irradiation and observation.

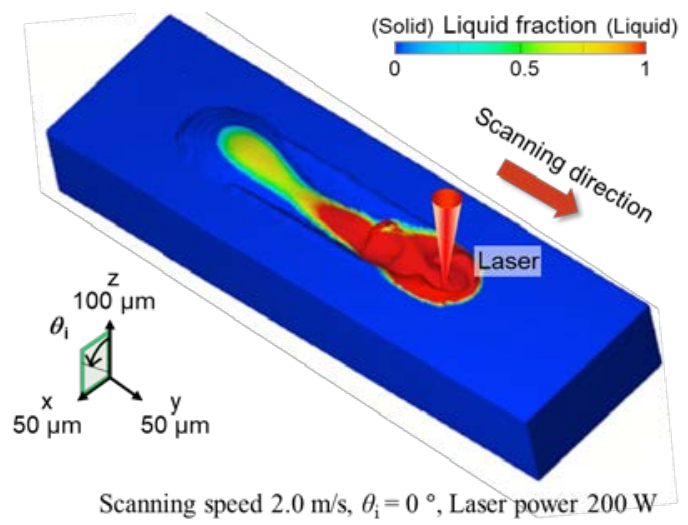

Fig. 4 Liquid fraction rate in thermal fluid analysis results in perpendicular irradiation.

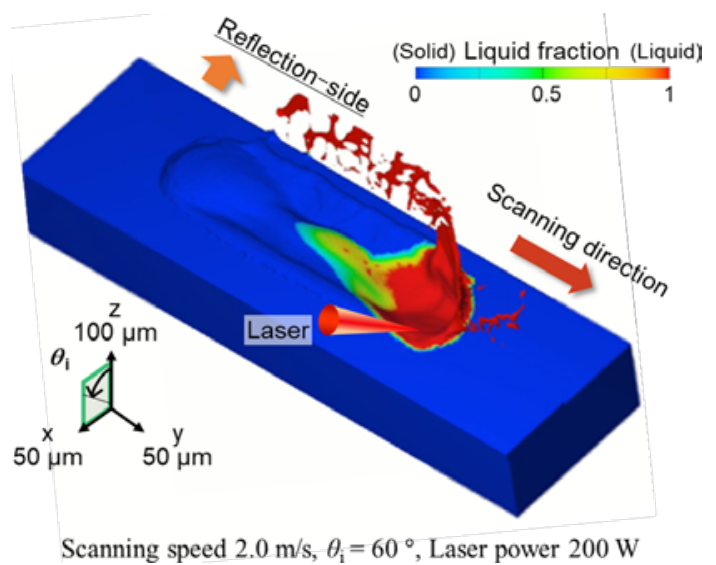

Fig. 5 Liquid fraction rate in thermal fluid analysis results in angled irradiation. 


\subsection{Solidification process of irradiation area by angled irradiation $\left(\theta_{\mathrm{i}}=60^{\circ}\right)$}

The detailed phenomena of angled irradiation are discussed in this section. Figure 6 shows the temporal variation of cross sectional shape and liquid fraction rate at the fixed point in the case of angled irradiation. In Fig. 6, 0 $\mu \mathrm{s}$ is defined as the time when the center of laser beam reaches the evaluation plane, and all figures are in the solidification stage of molten metal. The laser beam is irradiated from the right upper side, and the contour is liquid fraction rate as mentioned in Figs. 4 and 5. A keyhole exists at $0 \mu$ s along the beam axis of incident angle $\theta_{\mathrm{i}}=60^{\circ}$, and molten metal generated by heat conduction can be seen around the keyhole. From $0 \mu \mathrm{s}$ to $+20 \mu \mathrm{s}$, the molten area becomes large, and the volume of cavity without material also increases. From $+50 \mu$ s to $+80 \mu \mathrm{s}$, the cavity was partly filled by molten metal flow from the reflection-side to the incident-side, and an upheaval region appeared at the incident-side. Then, micro-groove can be observed at the reflection-side.

Figure 7 shows the analytical and experimental results of cross section, and 3D view of top surface in the case of angled irradiation $\theta_{\mathrm{i}}=60^{\circ}$, after material is solidified completely. The laser beam is irradiated from the right upper side in the figure, and the red dotted line indicates the region of resolidified area. The cross sections of both analytical and experimental results are similar shape, but the height of upheaval in the calculation result is a little smaller than that in the experimental one. In order to compare the cross sectional shape, the depth of resolidified area, the width of micro-groove, and the distance between the top of upheaval and the edge of resolidified area were measured. The relative error of their average values was approximately $\pm 7 \%$, and it is confirmed that the calculation results of thermal fluid analysis agree with the experimental results except for the upheaval shape.

\subsection{Molten metal flow around keyhole by angled irra- diation $\left(\theta_{\mathrm{i}}=60^{\circ}\right)$}

The behavior of molten metal flow in the microgrooving is discussed. Figure 8 shows the calculation results of thermal fluid analysis in the $x-y$ cross section with the liquid fraction rate. The top surface of specimen is set as $z=0 \mu \mathrm{m}$, and these results are at the depths of $11 \mu \mathrm{m}$, $21 \mu \mathrm{m}$, and $29 \mu \mathrm{m}$ below the top surface, respectively. The white area in the figure indicates a cavity due to the evaporation of material, which means no material area. The laser beam is irradiated from the lower side in the figures. The orange dotted lines indicate the scanning axis of laser beam, and the intersection of orange and white dotted line shows the laser beam position. The arrows in the liquid regions schematically represent the direction of molten metal flow analyzed by the thermal fluid analysis. As shown in the figure, a large volume of molten metal flow can be observed at the incident-side. Furthermore, it can be confirmed that the molten metal is flowing from the front to the rear of irradiation area. In addition, at $z=-29 \mu \mathrm{m}$, a unique flow was observed from the reflection-side to incident-side near the bottom of keyhole.

Next, the molten metal flow in the rear area of keyhole, which is confirmed by thermal fluid analysis, is compared with the results of high-speed observation.

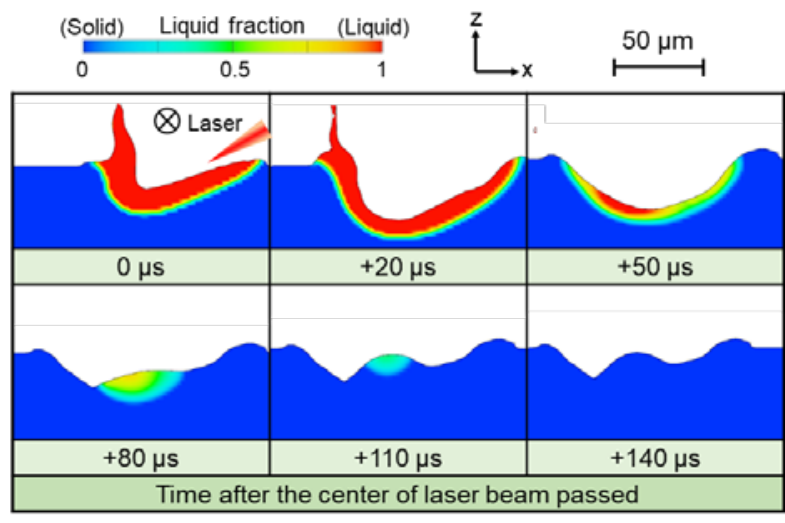

Scanning speed $2.0 \mathrm{~m} / \mathrm{s}, \theta_{\mathrm{i}}=60^{\circ}$, Laser power $200 \mathrm{~W}$

Fig. 6 Liquid fraction rate in analytical results of $x-z$ cross section during solidification in angled irradiation.

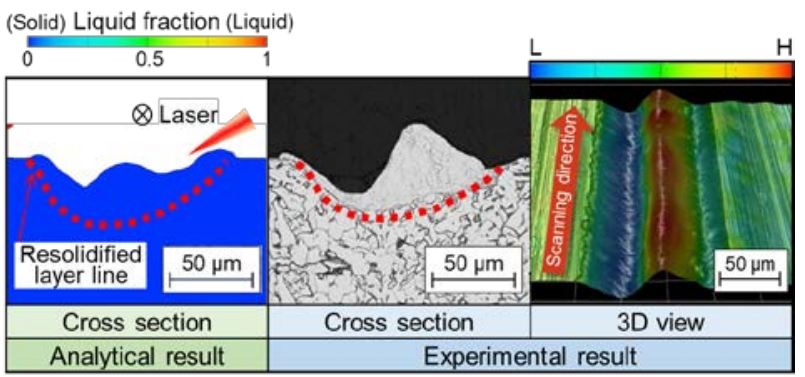

Scanning speed $2.0 \mathrm{~m} / \mathrm{s}, \theta_{1}=60^{\circ}$, Laser power $200 \mathrm{~W}$

Fig. 7 Liquid fraction rate in analytical and experimental results of $\mathrm{x}-\mathrm{z}$ cross section and 3D image of top surface in angled irradiation.

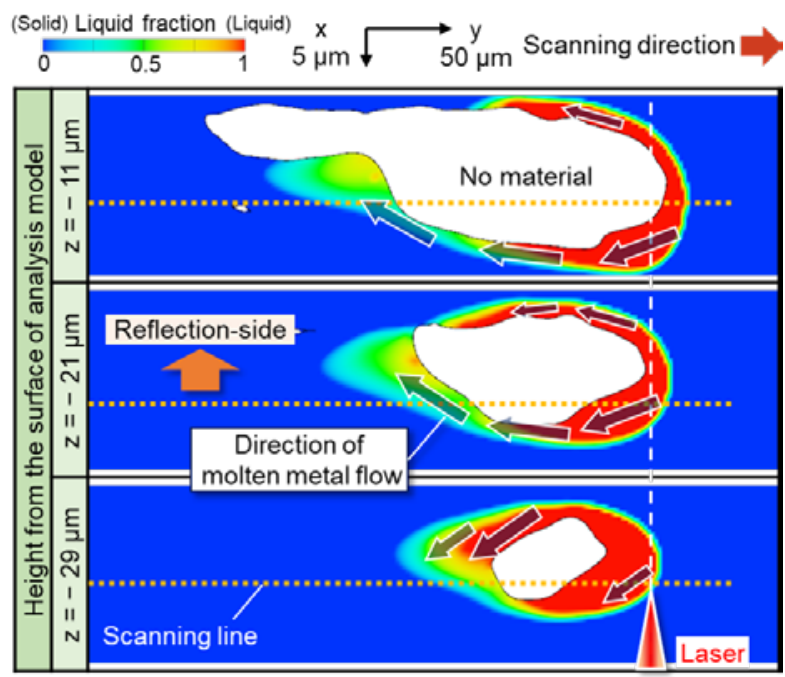

Scanning speed $2.0 \mathrm{~m} / \mathrm{s}, \theta_{\mathrm{i}}=60^{\circ}$, Laser power $200 \mathrm{~W}$

Fig. 8 Liquid fraction rate in analytical results of $x-y$ cross section at depth of $-11,-21,-29 \mu \mathrm{m}$ height from the specimen surface.

\subsection{Observation results by high-speed camera}

In order to discuss the scattering behavior of spatter on the plane perpendicular to scanning axis, the processing area in the angled irradiation was observed by high-speed camera, as shown in Fig. 3 (a). As shown in Fig. 9, the particles of molten metal clearly spread from the processing point and scattered toward the reflection-side as mentioned in analytical result of Fig. 5. 
Next, high-speed camera was set as shown in Fig. 3 (b), and the irradiation area was observed from the top side of specimen as shown in Fig. 10. Figs. 10 (a) and (b) show the observation results in the angled and the perpendicular irradiations. The laser beam was irradiated from the lower side, and keyhole and plasma could be recognized as the bright white areas. As shown in Fig. 10 (a), two molten metal flows were confirmed in the incident-side and the reflection-side, as mentioned in the analytical results. Then, these molten metal flows got together at the incident-side, and remained as the upheaval region of molten metal at the incident-side.

In addition, the direction of plume jet was noticed in both Figs. 10 (a) and (b). Comparing the angled irradiation with the perpendicular one, the direction of plume jet was different by the irradiation angle. Thus, the direction of recoil pressure was also different by the irradiation angle. It is considered that this difference of pressure direction affected the direction of molten metal flow in the rear area of keyhole. When micro-groove is formed by angled irradiation of CW laser, it can be said that the molten metal flow has a significant effect to the phenomena of microgrooving formation on metal surface.

\subsection{Mechanism of micro-groove formation by angled irradiation of $\mathbf{C W}$ laser}

Figure 11 summarizes micro-grooving phenomena in the $x-z$ and $x-y$ directions by both cases of perpendicular and angled irradiations. When a laser beam is irradiated perpendicularly as shown in the upper side of Fig. 11, keyhole and molten metal are generated. Then, the highspeed scanning and the recoil pressure create the cavity at the rear of keyhole. In this case, the molten metal flows symmetrically around the keyhole. Besides, molten metal flows from the bottom of keyhole to the cavity in the backward direction. Thus, an upheaval is formed at the center of scanning axis by gathering two flows of molten metal.

On the other hand, in the case of angled irradiation, high pressure field is generated at the reflection-side due to focusing situation of laser beam as shown in the lower side of Fig. 11. In addition, the top surface of molten metal is exposed to an air, the molten metal at the reflection-side scatters as spatters. The remained molten metal flows from the reflection-side to the incident-side through the bottom of keyhole, since the recoil pressure is generated from the reflection-side to the incident-side. Furthermore, the direction of recoil pressure toward to the incident-side generates more flow of molten metal to the incident-side. It is considered that these two flows of molten metal can keep the cavity at the reflection-side by high-speed scanning of laser beam, and the upheaval of molten metal exists at the incident-side. As a result, a micro-groove is formed on the reflection-side.

The fundamental formation phenomena of micro-groove by the perpendicular irradiation and the angled irradiation of CW laser were clarified by both analytical and experimental investigations. This micro-grooving process can be expected as a new micro-grooving method by using CW laser of lower power range.

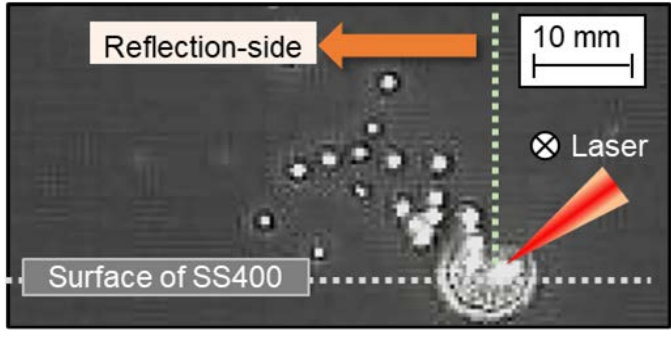

Shutter speed $43 \mu \mathrm{s}$, Frame rate 23,000 fps

Fig. 9 Scattering of spatter in angled irradiation $\left(\theta_{\mathrm{i}}=60^{\circ}\right)$.

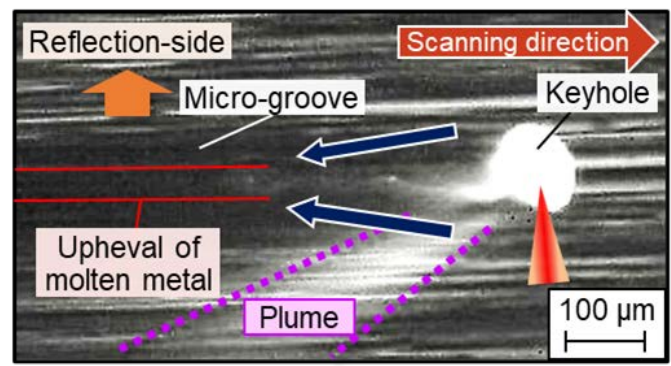

Shutter speed $10 \mu \mathrm{s}$, Frame rate 6,000 fps, Resolution $640 \times 320$ pixel

(a) Angled irradiation $\left(\theta_{\mathrm{i}}=60^{\circ}\right)$

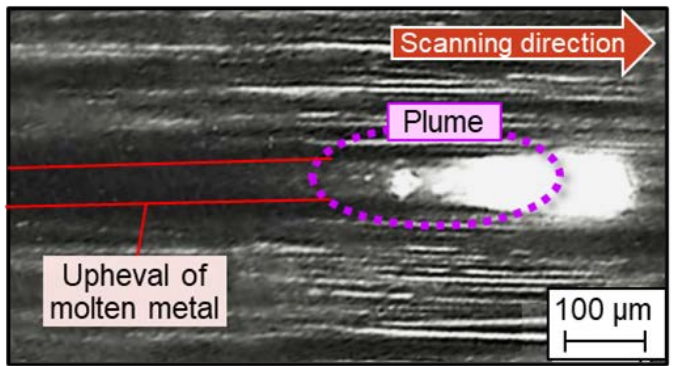

Shutter speed $10 \mu$ s, Frame rate 6,000 fps, Resolution $640 \times 320$ pixel

(b) Perpendicular irradiation $\left(\theta_{\mathrm{i}}=0^{\circ}\right)$

Fig. 10 Molten metal flows and explosion of plume from keyhole observed by high-speed camera.

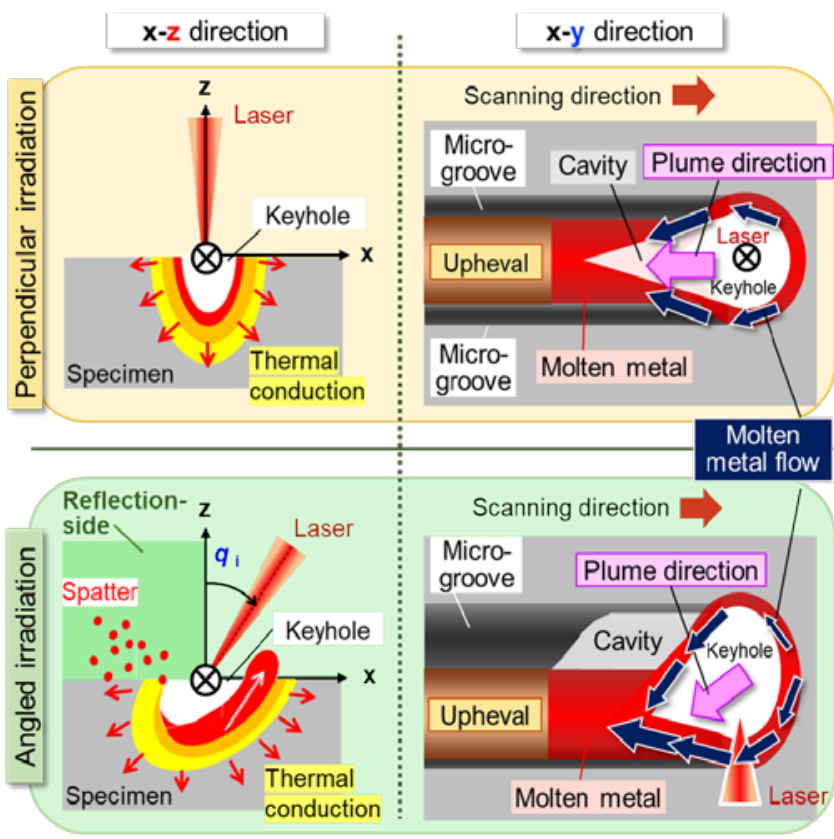

Fig. 11 Mechanism of micro-groove formation by using CW laser. 


\section{Conclusions}

The formation mechanism of micro-grooves in angled irradiation of $\mathrm{CW}$ laser with lower-average-power was discussed by thermal fluid analysis and high-speed camera observation. The main conclusions obtained in this study are as follows.

(1) Angled irradiation of CW laser on the plane perpendicular to the scanning axis creates different molten metal flows at the incident-side and the reflection-side, and the plume spouting from the keyhole can be observed diagonally at the backward incidentside under the high-speed scanning condition.

(2) In the angled irradiation of CW laser, the direction of recoil pressure affects the phenomena of molten metal flow in the rear area of keyhole, and the molten metal flow from the reflection-side to the incident-side appears at the bottom of cavity space created by keyhole generation and high-speed scanning.

(3) Asymmetrical behavior of molten metal flow in angled irradiation of CW laser can create micro-groove in the reflection-side at the high-speed scanning condition, and the micro-grooving process by using $\mathrm{CW}$ laser of lower-average-power can be used as a new microgrooving method.

\section{References}

[1] A. Dunn, J. V. Carstensen, K. L. Wlodarczyk, and E. B. Hansen: Opt. Laser Eng., 62, (2014) 9.

[2] A. Y. Farasi, S. Mwenifumbo, N. Rahbar, J. Chen, M. Li, A. C. Beye, C. B. Arnold, and W. O. Soboyejo: Mater. Sci. Eng. C, 29, (2009) 5.

[3] Y. Kawahito, A. Tange, S. Kubota, and S. Katayama: Proc. of the 25th Int. Cong. on Applications of Lasers \& Electro-Optics (ICALEO), (2006) Paper \#604.

[4] J. Lopez, G. Mincuzzi, R. Devillard, Y. Zaouter, C.
Hönninger, E. Mottay, and R. Kling: J. Laser Appl., 27, (2015) S28008.

[5] U. Loeschner, J. Schille, A. Streek, T. Knebel, L. Hartwig, R. Hillmann, and C. Endisch: J. Laser Appl., 27, (2015) S29303.

[6] E. Rodríguez-Vidal, C. Sanz, C. Soriano, J. Leunda, and G. Verhaeghe: J. Mater. Process. Technol., 229, (2016) 668.

[7] X. Z. Xie, Z. Q. Luo, X. Wei, F. L. Zhang, W. Hu, and Q. L. Ren: J. Laser Micro/Nanoeng., 11, (2016) 170.

[8] X. Z. Xie, Z. Y. Pan, X. Wei, F. M. Huang, W. Hul, and M. H. Hong: J. Laser Micro/Nanoeng., 6, (2011) 209.

[9] M. I. S. Ismail, Y. Okamoto, A. Okada, and Y. Uno: Am. J. Eng. Appl. Sci. 4, (2011) 306.

[10] C. Katayama, Y. Okamoto, T. Sakai, S. Kadonaga, and A. Okada: Proc. of the 8th Int. Conf. of Asian Society for Precision Engineering and Nanotechnology (ASPEN), (2019) B04-1-2.

[11] T. Sakai, Y. Okamoto, C. Katayama, H. Imai, and A. Okada: Appl. Sci., 10, (2020) 8333.

[12] A. Roesner, A. Olowinsky, and A. Gillner: Proc. of the 28th Int. Cong. on Applications of Lasers \& ElectroOptics (ICALEO), (2009) Paper \#132.

[13] P. Amend, S. Pfindel, and M. Schmidt: Phys. Procedia, 41, (2013) 98.

[14] B. Huang, L. Sun, L. Li, L. Zhang, Y. Lin, and J. Che: J. Mater. Process. Technol., 294, (2017) 407.

[15] C. W. Hirt, and B. D. Nichols: J. Compu. Phys., 39, (1981) 201.

[16] C. W. Hirt, and J. M. Sicilian: Int. Conf. on Numerical Ship Hydrodynamics 4th, (1985) 450.

[17] "Thermophysical properties handbook" ed. by Japan Society of Thermophysical Properties (Youkendou, Tokyo, 2008) p.210.

[18] A. A. Vostryakov, N. A. Vatolin, and O. A Yesin: Fizika Metall., 16, (1963) 675.

(Received: June 30, 2021, Accepted: October 3, 2021) 